\title{
Pattern of Pediatric Supracondylar Fracture Operated at A Rural Teaching Hospital of Nepal: A Descriptive Cross-sectional Study
}

\author{
Poojan Kumar Rokaya, 'Dhan Bahadur Karki, ${ }^{1}$ Mangal Rawal,' Deoman Limbu,' Suryaman Menyangbo, ${ }^{2}$ \\ Harihar Devkota ${ }^{2}$ \\ 'Department of Orthopedics \& Trauma Surgery, Karnali Academy of Health Sciences, Jumla, Karnali, Nepal, 2Department of \\ General Surgery, Karnali Academy of Health Sciences, Jumla, Karnali, Nepal.
}

\section{ABSTRACT}

Introduction: Supracondylar fracture of humerus is one of the common pediatric fractures encountered in our daily clinical practice. The purpose of this study is to determine the pattern of supracondylar fracture operated at rural teaching hospital of Jumla, Karnali Nepal.

Methods: A descriptive cross sectional study was conducted at Jumla, Karnali after Institutional Review Committee approval. Operating room notes from 15 May 2017 to 16 November 2019 were retrieved to gather the following information: patients address, age, sex, side, injury mechanism, displacement, neurovascular injury, concurrent injuries, initial management by traditional bone setters, time between injury and surgery, operative technique. Data analysis was done using Statistical Package for Social Sciences version 20.

Results: Left side predominated with 88 (63.7\%) and extension type was common in 135 (97.8\%). Thirteen $(9.4 \%)$ patients were initially managed by traditional bonesetters. A total of 138 children underwent operative fixation with mean age of 7.47 years and gender ratio of 2:1 boy to girl. Fall from cliff, ladders and rooftops were the prevailing cause of injury 73 (52.8\%). Average time between injury and surgery was 5.2 days. Closed reduction was done in 100 (72.4\%) patients whereas open reduction was necessary in $38(27.5 \%)$ patients.

Conclusions: Closed extension type pediatric supracondylar fracture was common in this study. Fall from cliff, rooftop and ladder are the major cause of fracture. Delayed presentation and initial management of the fracture by the traditional bonesetters makes supracondylar fracture more challenging in resource limited setting like ours.

Keywords: children; fracture; humerus; supracondylar.

\section{INTRODUCTION}

Supracondylar fracture of humerus is one of the commonest fractures encountered in our daily clinical practice. They account for $50 \%$ to $70 \%$ of all pediatric elbow fractures and represent approximately $17 \%$ of all paediatric fractures. ${ }^{1}$ It occurs primarily between 5-8 years of age with equal incidence among males and females. ${ }^{2}$ About $98 \%$ of these fractures are classified as extension type and usually result from fall onto outstretched hand with the elbow in full extension and wrist in dorsiflexion. ${ }^{3}$ Most fractures occur on the left side with posteromedial displacement being common in $75 \%$ of the cases. ${ }^{4}$
Immediate neurovascular injury and potential complications like cubitus varus deformity, compartment syndrome, Volkmann ischemic contracture and trochlear osteonecrosis make supracondylar fracture a serious injury. ${ }^{5}$ Delayed presentation due to lack of transport, uneven geographical topography, massage by a traditional bonesetter and negligence by the parents has made supracondylar fracture more challenging in our setup. The current trend in our hospital for the treatment of displaced supracondylar fractures is closed

Correspondence: Dr. Poojan Kumar Rokaya, Department of Orthopedics \& Trauma Surgery, Karnali Academy of Health Sciences, Jumla, Karnali, Nepal. Email: pkr2039@gmail.com, Phone: +977. 9849083461 . 
reduction percutaneous pinning (CRPP), when closed reduction fails with three attempts open reduction internal fixation (ORIF) is performed.

The purpose of this study is to determine the pattern and treatment characteristics of paediatric supracondylar fracture operated at rural teaching hospital of Jumla, Karnali Nepal.

\section{METHODS}

After Institutional Review Committee approval (IRC No.076/077/03) single center descriptive cross sectional study was conducted at Karnali Academy of Health Sciences teaching hospital Jumla, Nepal. Operating room notes from Jestha 2074 to Kartik 2076 (15 May 2017 to 16 November 2019) over a period of 30 months were retrieved to gather the following information: patients address, mode of injury, age, sex, side, extension or flexion mechanism, displacement, closed or open fracture, neurovascular injury, concurrent injuries, initial management by traditional bone setters, time between injury and surgery, CRPP or ORIF, approach for ORIF and intraoperative complication. Children age $\leq 14$ years managed surgically with CRPP or ORIF for supracondylar fracture with complete records was included in the study. Exclusion criteria included: Patient age $>15$ years, incomplete medical record and supracondylar fracture managed conservatively in plaster slab. Dataanalysis was done using Statistical Package for Social Sciences (SPSS Inc. version 20, Chicago, Illinois) to find out the mean, average and range.

\section{RESULTS}

Altogether 138 children were managed surgically for supracondylar fracture over a period of 30 months. The geographical distribution of patients is shown (Figure 1).

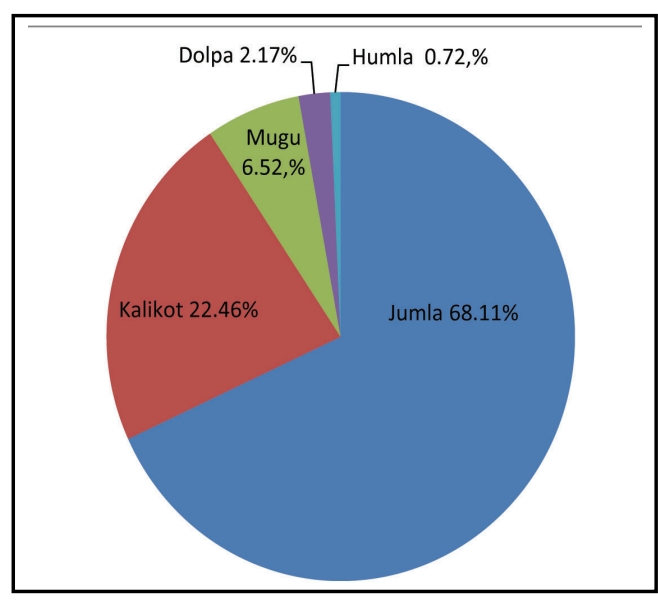

Figure 1. Geographic distribution of patients.
The demographic data including patient and fracture pattern is mentioned (Table 1).

Table 1. Patient and fracture pattern.

\begin{tabular}{|c|c|c|}
\hline Variables & & n (\%) \\
\hline \multirow[t]{2}{*}{ Sex } & Male & $93(67.3)$ \\
\hline & Female & $45(32.6)$ \\
\hline \multirow[t]{2}{*}{ Side } & Right & $50(36.2)$ \\
\hline & Left & $88(63.7)$ \\
\hline \multirow[t]{7}{*}{ Mode of injury } & Fall while playing & 57 (41.3) \\
\hline & Fall from cliff & $34(24.6)$ \\
\hline & Fall from ladder & 22 (15.9) \\
\hline & Fall from rooftop & $17(12.3)$ \\
\hline & Fall from horse & $3(2.1)$ \\
\hline & Fall from bicycle & $3(2.1)$ \\
\hline & Fall from ox & $2(1.4)$ \\
\hline \multirow[t]{2}{*}{ Fracture type } & Open & $4(2.8)$ \\
\hline & Close & $134(97.1)$ \\
\hline \multirow[t]{2}{*}{ Mechanism } & Flexion & $3(2.1)$ \\
\hline & Extension & $135(97.8)$ \\
\hline \multirow[t]{2}{*}{ Gartland type } & Type II & $17(12.5)$ \\
\hline & Type III & $118(87.4)$ \\
\hline \multirow[t]{2}{*}{ Displacement } & Posterolateral & $39(28.8)$ \\
\hline & Posteromedial & $96(71.1)$ \\
\hline \multirow{3}{*}{$\begin{array}{l}\text { Nerve vascular } \\
\text { injury }\end{array}$} & Brachial artery injury & $1(0.7)$ \\
\hline & Median nerve injury & $5(3.6)$ \\
\hline & Ulnar nerve injury & $2(1.4)$ \\
\hline \multirow[t]{3}{*}{$\begin{array}{l}\text { Concurrent } \\
\text { fractures }\end{array}$} & $\begin{array}{l}\text { Ipsilateral radius and } \\
\text { ulna fracture }\end{array}$ & $4(2.8)$ \\
\hline & $\begin{array}{l}\text { Ipsilateral clavicle } \\
\text { fracture }\end{array}$ & $1(0.7)$ \\
\hline & $\begin{array}{l}\text { Ipsilateral radius } \\
\text { and proximal } \\
\text { humerus fracture }\end{array}$ & $1(0.7)$ \\
\hline
\end{tabular}

In this study boy to girl ratio was 2:1 with a mean age of 7.47 years (Range 2-14 years). Fall from cliff, ladders and rooftops were the major mode of injury accounting for $52.8 \%$. Fracture occurred predominantly on the left side with 63.7\%. Approximately 135 (97.8\%) patients had extensor mechanism with posteromedial displacement being common in $96(71.1 \%)$ patients. There were $134(97.1 \%)$ closed fractures and four $(2.8 \%)$ open fractures. Neurovascular injury was seen in seven (5\%) patients. Concurrent fracture was found in six $(4.3 \%)$ patients. Thirteen out of 138 (9.4\%) patients were initially managed by traditional bonesetters and faith healers. Average duration from day of injury to day of surgery was 5.2 days (Range 2-14 days). The 
pattern of operative technique is tabulated (Table 2). CRPP was done in 100 (72.4\%) patients whereas 38 $(27.5 \%)$ patients required ORIF.

\begin{tabular}{|lll|}
\hline \multicolumn{2}{|l|}{ Table 2. Operative technique. } \\
\hline Variables & $\mathbf{n}(\%)$ \\
Operative technique & ORIF & $38(27.5)$ \\
& CRPP & $100(72.4)$ \\
Approach for ORIF & Anterior & $1(2.6)$ \\
& Medial & $9(23.6)$ \\
& Posterior & $28(73.6)$ \\
\hline
\end{tabular}

\section{DISCUSSION}

This study reflects the epidemiological parameters of pediatric supracondylar fracture operated at a rural orthopedic setup of Nepal. All the patients belonged to Karnali province. Majority were permanent resident of Jumla $(68.11 \%)$ followed by Kalikot $(22.46 \%)$, Mugu (6.52\%), Dolpa (2.17\%) and Humla district (0.72\%). In this study, the mean age of the patient was 7.47 years (2-14 years) which is similar to other studies. ${ }^{6,7}$ Male outnumbered female with 2:1 male to female ratio. Our gender ratio is in consistent with the study conducted by Okubo et al although recent studies have found nearly equal incidence among both sexes. ${ }^{8}$ Fracture occurred predominantly in the left side involving $63.7 \%$ of total cases in this study. Protective posture assumed by the non-dominant extremity during fall could be the likely cause. Fall onto outstretched hand from cliff, rooftop and ladder were the common mode of injury observed in this study accounting for $52.8 \%$ of total falls. Children occasionally climb cliff to cut grass for household purpose in mountain districts like Jumla, Kalikot, and Mugu. Rooftops in the remote villages are usually open and lack protective bars or railings. Wooden ladders present in houses are devoid of side bars in most of the rural community of Karnali province. Extension type of fracture was noted in 135 (97.8\%) patients whereas flexion type was noted in three $(2.1 \%)$ patients which is comparable with previous studies. ${ }^{9,10}$ Posteromedial displacement of the distal fragment was seen in approximately $71.1 \%$ of patients in our series which is compatible with other studies. ${ }^{11}$ Four $(2.8 \%)$ patients presented with open fracture in this series which coincides with the study conducted by Mangwani et al. ${ }^{6}$ Preoperative neurovascular injury was documented in seven ( $5 \%$ ) patients. Median nerve was injured in five patients whereas two patients had ulnar nerve injury. One patient with open fracture had median nerve injury and pink pulseless hand. Pulse returned upon fixation of fracture via anterior approach. L.V. Barr in his series of 159 supracondylar fracture reported neurovascular injury in six $(3.7 \%)$ patients. ${ }^{12}$ Concurrent fractures were found in six $(4.3 \%)$ patients in this study. Four patients had ipsilateral fracture of the distal third of forearm bones, one patient had ipsilateral clavicle fracture and one patient had ipsilateral fracture of distal radius and proximal humerus. Concurrent fractures in pediatric supracondylar fracture have been reported up to $5 \%$ in the literature. ${ }^{13}$ Average duration between day of injury and day of surgery was 5.2 days (2-14 days). Delayed presentation is not uncommon in our hospital due to lack of transport, uneven geographical topography and initial management by traditional bonesetter. In this study, $13(9.4 \%)$ patients were initially managed by traditional bonesetters and faith healers. Lack of awareness, poverty and unavailability of nearby health facility could have promoted faith healers and traditional bone setters in remote areas of lower income country like ours. ${ }^{14,15}$ Moreover, negligence by the parents to seek medical advice has made supracondylar fracture more challenging in our rural community which could alter the outcome of management.

CRPP was successful in 100 (72.4\%) patients whereas ORIF was inevitable in $38(27.5 \%)$ patients. The rate of ORIF for supracondylar fracture in published literature ranges from $1.3 \%$ to $46 \% .^{16}$ Closed reductions usually fails when there is massive elbow swelling, low lying fracture, pillar communition, positive pucker sign and Gartland Type IV supracondylar fracture. ${ }^{17,18}$ Delayed presentation could be one of the potential causes for failure of closed reduction in our study. Among 38 patients who underwent ORIF, 28 patients were approached through posterior triceps splitting approach, 9 patients through medial approach and one patient with neurovascular injury through anterior approach. Surgical approach for ORIF was decided as per operating surgeon's preference, experience and fracture personality. There is paucity in the literature regarding the standard approach which brings about better functional and radiological outcome with minimal complications. Open reduction via posterior approach is easy to perform, provides access to both the cortex at a time but it is associated with higher rate of loss of ROM and trochlear osteonecrosis. ${ }^{19}$ The merits of medial approach are lesser chance of iatrogenic ulnar nerve injury and unsightly scar. ${ }^{20}$ The preferred surgical approach should allow for anatomic reduction, access to involved neurovascular structures, satisfactory cosmetic and functional outcomes with minimal complications. ${ }^{21}$

Our study was dependent solely upon operating room data which is one of the major limitations. We could not include postoperative complications and treatment outcome because of poor patient compliance in regular follow up. 
In our opinion this is the first rural population based study in Nepal to investigate the pattern of pediatric supracondylar fracture. Multi centric study should be conducted in other rural parts of the country to validate this study.

\section{CONCLUSIONS}

Closed extension type of pediatric supracondylar fracture was common in this study. It was prevalent in boys and predominantly involved the non-dominant side. Fall from cliff, rooftop and ladder are the major preventable cause of fracture in the rural community of Karnali Nepal. Delayed presentation makes supracondylar fracture more challenging in resource limited setting like ours. Initial management of the fracture by the traditional bonesetters could alter the outcome of surgical treatment.

We recommend the stakeholders to take initiation in preventing falls by securing the rooftops and ladders. Traditional bone setters and faith healers should be counseled to minimize the morbidity. Government should raise awareness in the rural community regarding preventable injuries, establish health facility in remote parts and strengthen the existing health referral system.

\section{Conflict of Interest: None.}

\section{REFERENCES}

1. Brown IC, Zinar DM. Traumatic and iatrogenic neurological complications after supracondylar humerus fractures in children. J Pediatr Orthop. 1995;15(4):440-3. [PubMed | $\underline{\mathrm{DOI}}$

2. Cheng JC, Lam TP, Maffulli N. Epidemiological features of supracondylar fractures of the humerus in Chinese children. J Pediatr Orthop B. 2001;10(1):63-7. [PubMed]

3. O' Hara LJ, Barlow JW, Clarke NM. Displaced supracondylar fractures of the humerus in children. Audit changes practice. J Bone Joint Surg Br.2000;82(2):204-10. [PubMed]

4. Skaggs DL, Flynn JM. Supracondylar fractures of the distal gumerus. In: Beaty JH, Kasser JR. Rockwood and Wilkins' fractures in children, 8th ed. Philadelphia, PA: Lippincot Williams \& Wilkins; 2015. p. 581-627. [Full Text]

5. Uzer G, Yildiz F, Elmadag M, Bilsel K, Erden T, Pulatkan A, et al. Comparison of the lateral and posterior approaches in the treatment of pediatric supracondylar humeral fractures. J Pediatr Orthop B. 2018;27(2):108-114. [․ㅏbMed | DOI]

6. Mangwani J, Nadarajah R, Paterson JM. Supracondylar humeral fractures in children: ten years' experience in a teaching hospital. J Bone Joint Surg Br. 2006;88(3):362-5. [PubMed]

7. Khoshbin A, Leroux T, Wasserstein D, Wolfstadt J, Law PW, Mahomed N, et al. The epidemiology of paediatric supracondylar fracture fixation: a population-based study. Injury. 2014;45(4):701-8. [ubMed | DOI]

8. Okubo H, Nakasone M, Kinjo M, Onaka K, Futenma C, Kanaya F. Epidemiology of paediatric elbow fractures: a retrospective multi-centre study of 488 fractures. J Child Orthop. 2019;13(5):516-21. [PubMed | DOI]

9. Barron-Torres EA, Sanchez-Cruz JF, Cruz-Melendez JR. Clinical and epidemiological characteristic of humeral supracondylar fractures in pediatric patients in a Regional General Hospital. Cir. Cir. 2015;83(1):29-34. [PubMed]
10. Mahan ST, May CD, Kocher MS. Operative management of displaced flexion supracondylar humerus fractures in children. J Pediatr Orthop. 2007;27(5):551-6. [PubMed]

11. Louahem DM, Nebunescu A, Canavese F. Neurovascular complications and severe displacement in supracondylar humerus fractures in children: Defensive or offensive strategy? J Pediatr Orthop B. 2006;15(1):51-7. [PubMed |DOI]

12. Barr LV. Paediatric supracondylar humeral fractures: epidemiology, mechanisms and incidence during school holidays. J Child Orthop. 2014;8(2):167-70. [PubMed]

13. Anjum $R$, Sharma V, Jindal $R$, Singh TP, Rathee $N$. Epidemiologic pattern of paediatric supracondylar fractures of humerus in a teaching hospital of rural India: A prospective study of 263 cases. Chin J Traumatol. 2017;20(3):158-160. [PubMed]

14. Nwachukwu BU, Okwesili IC, Harris MB, Katz JN. Traditional bonesetters and contemporary orthopaedic fracture care in a developing nation: historical aspects, contemporary status and future directions. Open Orthop J. 2011;5:20-6. [PubMed]

15. Omololu AB, Ogunlade SO, Gopaldasani VK. The practice of traditional bonesetting: training algorithm. Clin Orthop Relat Res. 2008;466(10):2392-8. [PubMed]

16. Gupta N, Kay RM, Leitch K, Femino JD, Tolo VT, Skaggs DL. Effects of surgical delay on perioperative complications and need for open reduction in supracondylar humerus fractures in children. J Paediatr Orthop. 2004;24(3):245-8. [PubMed | DOI]

17. Smuin D.M, Hennrikus WL. The effect of the pucker sign on outcomes of type III extension supracondylar fractures in children. J Pediatr Orthop. 2017;37(4):e229-e32 [PubMed | DOI]

18. Leitch KK, Kay RM, Femino JD, Tolo VT, Storer SK, Skaggs DL. Treatment of multidirectionally unstable supracondylar humeral fractures in children. A modified Gartland type-IV fracture. J Bone Joint Surg Am. 2006;88(5):980-5. [PubMed] 
19. Aktekin CN, Toprak A, Ozturk AM, Altay M, Ozkurt B, Tabak AY. Open reduction via posterior triceps sparing approach in comparison with closed treatment of posteromedial displaced Gartland type III supracondylar humerus fractures. J Pediatr Orthop B. 2008;17(4):171-8. [pubMed]
20. Barlas K, Baga T. Medial approach for fixation of displaced supracondylar fractures of the humerus in children. Acta Orthop Belg. 2005;71(2):149-53. [PubMed]

21. Pretell Mazzini J, Rodriguez Martin J, Andres Esteban EM. Surgical approaches for open reduction and pinning in severely displaced supracondylar humerus fractures in children: A systematic review. J Child Orthop. 2010;4(2):14352. [PubMed | DOI]

This work is licensed under a Creative Commons Attribution 4.0 International License. The images or other third party material in this article are included in the article's Creative Commons license, unless indicated otherwise in the credit line; if the material is not included under the Creative Commons license, users will need to obtain permission from the license holder to reproduce the material. To view a copy of this license, visit http://creativecommons.org/licenses/by/4.0/ 